\title{
POLA PERJALANAN BERANGKAT BEKERJA MENGGUNAKAN LAYANAN TRANSJAKARTA (STUDI KASUS: PERUMAHAN SUNTER HIJAU VIII- SUNTER JAYA, DAN PERUMAHAN TAMAN BUARAN INDAH IV, PENGGILINGAN, PENGGILINGAN)
}

\author{
Yudi Susandi ${ }^{1}$ dan Danang Priatmodjo ${ }^{2}$ \\ ${ }^{1}$ Mahasiswa Magister Teknik Perencanaan, Universitas Tarumanagara, Jakarta \\ Surel: ysmifx@gmail.com \\ ${ }^{2}$ Dosen Magister Teknik Perencanaan, Universitas Tarumanagara, Jakarta \\ Surel: danang_priatmodjo@yahoo.com
}

\begin{abstract}
Increased mobility in urban areas is caused by a variety of factors, one of which is the increasing rate of urbanization from year to year caused by how cities seem more promising compared to rural areas to the productive age population. The city of Jakarta also experienced the same thing, recorded from 2013-2016 the number of urbanization always increases by 1$1.5 \%$ each year, with a total population in 2016 of 10.2 million people. As the population continues to increase, there is more need for land that is planned for housing. Land in the city center has already been filled with offices and trade centers, making land prices for housing hardly affordable. This results in residents choosing housing that is located on the outskirts of the city or completely outside the administrative limits of the city center itself, and daily, each individual has to travel to do their respective activities, various activities that lead to mobility. For the city of Jakarta which has 14.5 million people during the day this certainly becomes a challenge of enormous mobility problems. Efforts of the Jakarta Provincial Government to overcome the mobility problems of the citizens of Jakarta include the BRT Transjakarta transportation service the Jakarta Provincial Government came up with in 2004. As we know, in order for a certain system to meet the needs of its users, it must be designed to suit the needs of its users. The purpose of this study is to explore commuting patterns of citizens of Jakarta using Transjakarta services. This study uses Collective Case Study method with descriptive qualitative approach, with 13 (thirteen) participants who use the Transjakarta transportation service daily to commute to work. The results of this study include: the distance traveled in relatively long distances caused by the separation of zoning that is too far between residential and commercial areas, the unreliability public transportation outside the Transjakarta BRT places more burden on community mobility services, travel time and low average cruising speed, the user of the Transjakarta BRT service contributes positively to the use of motorbikes used within a radius of $<5 \mathrm{Km}$, and there are still many aspects that need to be addressed so that the Transjakarta BRT service becomes a reliable service that can meet the needs of its users. The recommendations of the results of this study are aimed at urban planners and urban transport planners who are very closely related to the success of the city in designing more livable cities. PT. Transjakarta transportation for Transjakarta BRT transportation services that is more reliable, in terms of time and operational costs, and better quality of public transportation services in serving all levels of society in Jakarta Metropolitan City.
\end{abstract}

Keywords: Travel Pattern, Transjakarta BRT System. 


\begin{abstract}
ABSTRAK
Meningkatnya mobilitas di perkotaan disebabkan oleh berbagai macam faktor, diketahui salah satunya adalah semakin meningkatnya tingkat urbanisasi dari tahun ke tahun yang disebabkan oleh lebih menariknya perkotaan dibandingkan daerah rural di mata kalangan penduduk usia produktif. Kota Jakarta pun mengalami hal yang serupa, tercatat dari tahun 2013-2016 jumlah urbanisannya selalu meningkat 1-1,5\% tiap tahunnya, dengan total penduduk pada tahun 2016 sebesar 10,2 juta jiwa. Seiring dengan terus bertambahnya jumlah penduduk tersebut tentu lahan-lahan yg diperuntukan untuk pemukiman juga diharuskan bertambah, lahan pusat kota sudah banyak terisi oleh perkantoran dan pusat-pusat perdagangan menyebabkan harga lahan untuk pemukiman menjadi sulit untuk dijangkau. Hal ini mengakibatkan para penduduk memilih hunian yang agak di pinggir kota ataupun benar-benar keluar dari batasan administrasi pusat kota itu sendiri, dan dalam kesehariaannya setiap individu melakukan perjalanan dalam memenuhi aktivitas kegiatan masing-masing, berbagai aktivitas kegiatan tersebut menimbulkan sebuah mobilitas). Untuk kota DKI Jakarta yg memiliki 14,5 Juta Jiwa pada siang hari hal ini tentu menjadi sebuah tantangan permasalahan mobilitas yang sangat besar, usaha Pemprov DKI Jakarta untuk mengatasi permasalahan mobilitas warga kota DKI Jakarta salah satunya adalah pada tahun 2004 Pemprov DKI Jakarta mencetuskan layanan transportasi BRT Transjakarta. Seperti yang kita ketahui agar suatu sistim tertentu dapat memenuhi kebutuhan penggunanya maka diharuskan dirancang agar sesuai untuk keperluan para penggunanya. Tujuan penelitian ini untuk mengeksplorasi pola-pola perjalanan berangkat bekerja dengan menggunakan layanan Transjakarta pada penghuni perumahan di Kota Jakarta, penelitian ini menggunakan metode Collective Case Study dengan pendekatan kualitatif deskriptif, banyaknya partisipan dari penelitian ini berjumlah 13 (tiga belas) partisipan yang kesehariannya menggunakan layanan transportasi Transjakarta untuk berangkat bekerja. Temuan hasil penelitian ini antara lain: jarak tempuh perjalanan dalam jarak relative jauh yang disebabkan oleh pemisahan zonasi yang terlalu jauh antara residential-komersial, ketidakhandalan transportasi umum diluar BRT Transjakarta memberikan beban lebih pada pelayanan mobilitas masyarakat, waktu tempuh dan kecepatan jelajah rata-rata masih rendah, penggunaa layanan BRT Transjakarta memberikan kontribusi positif pada penggunaan sepeda motor yang digunakan dalam radius $<5 \mathrm{Km}$, dan masih banyaknya aspek yang perlu dibenahi agar layanan BRT Transjakarta menjadi layanan yang handal dan dapat memenuhi kebutuhan penggunanya. Rekomendasi hasil penelitian ini ditujukan untuk perancang kota dan perancang transportasi perkotaan yang sangat berhubungan erat dengan kesuksesan kota dalam perancangan kota yang lebih layak huni. PT. Transportasi Transjakarta untuk layanan transportasi BRT Transjakarta yang lebih handal, reliable dalam waktu dan biaya operasional, serta kualitas pelayanan transportasi publik yang lebih baik lagi dalam melayani seluruh lapisan masyarakat Kota Metropolitan Jakarta.
\end{abstract}

Kata kunci: Pola Perjalanan, BRT System Transjakarta.

\title{
1. PENDAHULUAN
}

Urbanisasi, diketahui $50 \%$ dari seluruh penduduk dunia pada saat ini bertempat tinggal di urban area, dan diketahui juga $60 \%$ penduduk Indonesia bertempat tinggal di urban area ataupun rural area yang bertransformasi menjadi urban area. Urbanisasi juga berperan sebagai salah satu faktor yang mempengaruhi peningkatan mobilitas di perkotaan dan permintaan kebutuhan pemukiman, urbanisasi terjadi dikarenakan pandangan kaum produktif yang berpendapat bahwa perkotaan lebih menarik dibandingkan dengan daerah rural dan tentu saja kota dianggap memiliki kesempatan yang lebih besar dari daerah rural tempat para urbanisan berasal. Tercatat dari tahun 2013-2016 jumlah urbanisan di DKI Jakarta selalu meningkat 1-1,5\% tiap tahunnya 
(sumber: http://Jakarta.bps.go.id) hal ini tidak dapat dihindari oleh kota, karena kota tidak dapat mencegah orang yang ingin datang ke kota tersebut. Dan tentu saja hal yang patut sekali menjadi sebuah fokus penyelesaian permasalahan kota adalah efisiensi dan efektivitas sebuah perjalanan yang diperuntukan bagi mobilitas seluruh masyarakat yang beraktivitas di kota tersebut (Therese, 2008), dan hal ini merupakan permasalahan yang patut diberikan perhatian lebih oleh para perancang kota dan perancang transportasi perkotaan. Dengan bertambahnya penduduk yang disebabkan oleh arus urbanisasi tentu saja kebutuhan lahan-lahan pemukiman diharuskan bertambah, lahan pusat kota yang sudah penuh dengan perkantoran dan pusat-pusat perdagangan menyebabkan harga lahan untuk pemukiman menjadi tidak terjangkau, maka pilihannya adalah daerah yang agak di pinggir kota ataupun benar-benar keluar dari batas administrasi kota itu sendiri (Priatmodjo, 1997). Dan seiring dengan perkembangan kota yang terjadi berdekade silam, Kota Jakarta menjadi sebuah kota megapolitan yang berpenduduk 14,5 juta jiwa pada siang hari dan 10,2 juta jiwa pada malam hari, selisih dari jumlah penduduk tersebut adalah para traveler yang memiliki keterkaitan antar batas wilayah yang banyak berperan sebagai penggerak ekonomi pusat kota dan kota-kota disekitarnya (Sugiyarto, 2008). Sebagai konsekuensi dari keterkaitan antar wilayah dan pola sebaran tata guna lahan itu sendiri menciptakan sebuah perjalanan (Tamim, 1997), dimana efek sebuah perjalanan yang dilakukan secara terus menerus adalah penciptaan sebuah pola (Lee, 2003). Sejak tahun 2004 pemprov DKI Jakarta menciptakan transportasi umum BRT Transjakarta yang mencontoh pada Transmilenio Bogota untuk mengurai kemacetan jalanan dan sebagai alat mobilitas bagi seluruh masyarakat Kota Jakarta (Undp, 2015). Kota Jakarta memiliki tingkat kemacetan yang sangat tinggi, fokus pembenahan permasalahan kemacetan ini pun tertuang dalam salah satu program utama Jakarta Resilient City, Public Transport menjadi fokus penyelesaian permasalahan kemacetan tersebut (Oswar, 2016). Menurut data, jumlah kendaraan yang terdaftar di wilayah DKI Jakarta sebanyak 48.859.525 unit kendaraan pada tahun 2016 (sumber: ditlantas polda metro jaya), sedangkan pada tahun yang sama luasan ruas jalan yang tersedia hanya sebesar $43.710 .847 \mathrm{~m} 2$ (sumber: dinas pekerjaan umum provinsi DKI Jakarta) tentu saja hal ini sudah dapat menunjukkan diperlukannya perubahan pola mobilitas dari kendaraan pribadi dialihkan ke penggunaan Public Transport (Ursa, 2015). Tujuan dari penelitian ini adalah untuk meneliti bagaimana pola-pola perjalanan berangkat bekerja para pengguna Transjakarta di kawasan perumahan Sunter Hijau dan perumahan Taman Buaran Indah IV.

\section{METODE PENELITIAN}

Penelitian ini menggunakan pendekatan kualitatif dengan metode collective case study dan menggunakan 13 partisipan untuk kedua lokasi penelitian dengan rincian 6 partisipan pada lokasi trip generator perumahan Sunter Hijau dan 7 partisipan pada lokasi trip generator perumahan Taman Buaran Indah IV, Alasan pertama dipilihnya kedua perumahan tersebut adalah agar dapat memberikan perbandingan pola perilaku masyarakat perumahan yang lokasi nya agak jauh dan sangat dekat dengan halte transjakarta dari perumahan tersebut, akan tetapi jarak tersebut masih dapat dijangkau dengan baik sehingga tidak mengurangi ketertarikan para calon penggunanya. Alasan kedua adalah masyarakat perumahan tersebut memiliki karakter tingkat ekonomi yang berbeda, dimana perumahan Sunter Hijau memiliki karakter tingkat ekonomi yang lebih tinggi dibandingkan perumahan Taman Buaran Indah IV. Jangkauan penelitian ini meliputi keseluruhan pola seperti (moda split yang digunakan untuk mengakses layanan Transjakarta, berapa banyak total moda split yang digunakan untuk sampai ke tempat kerja, berapa jarak ratarata berangkat bekerja dan berapa waktu tempuh perjalanannya, berapa pengeluaran per trip perjalanan dan berapa pengeluaran perbulannya bila dibandingkan dengan pendapatan, serta faktor-faktor yang berkaitan dengan pola perjalanan berangkat bekerja dengan menggunakan 
layanan Transjakarta). Waktu studi dilakukan mulai dari bulan Februari-Mei 2018 dengan metode pengumpulan data wawancara dan observasi secara bersamaan per partisipan.

\section{HASIL DAN PEMBAHASAN}

Partisipan dalam penelitian ini berada dalam rentang umur 19-67 tahun yang terdiri dari 6 orang partisipan di lokasi penelitian 1 (perumahan Sunter Hijau-Sunter Jaya, Tanjung Priok, Jakarta Utara) dan 7 orang partisipan di lokasi penelitian 2 (perumahan Taman Buaran Indah IVPenggilingan, Cakung, Jakarta Timur).

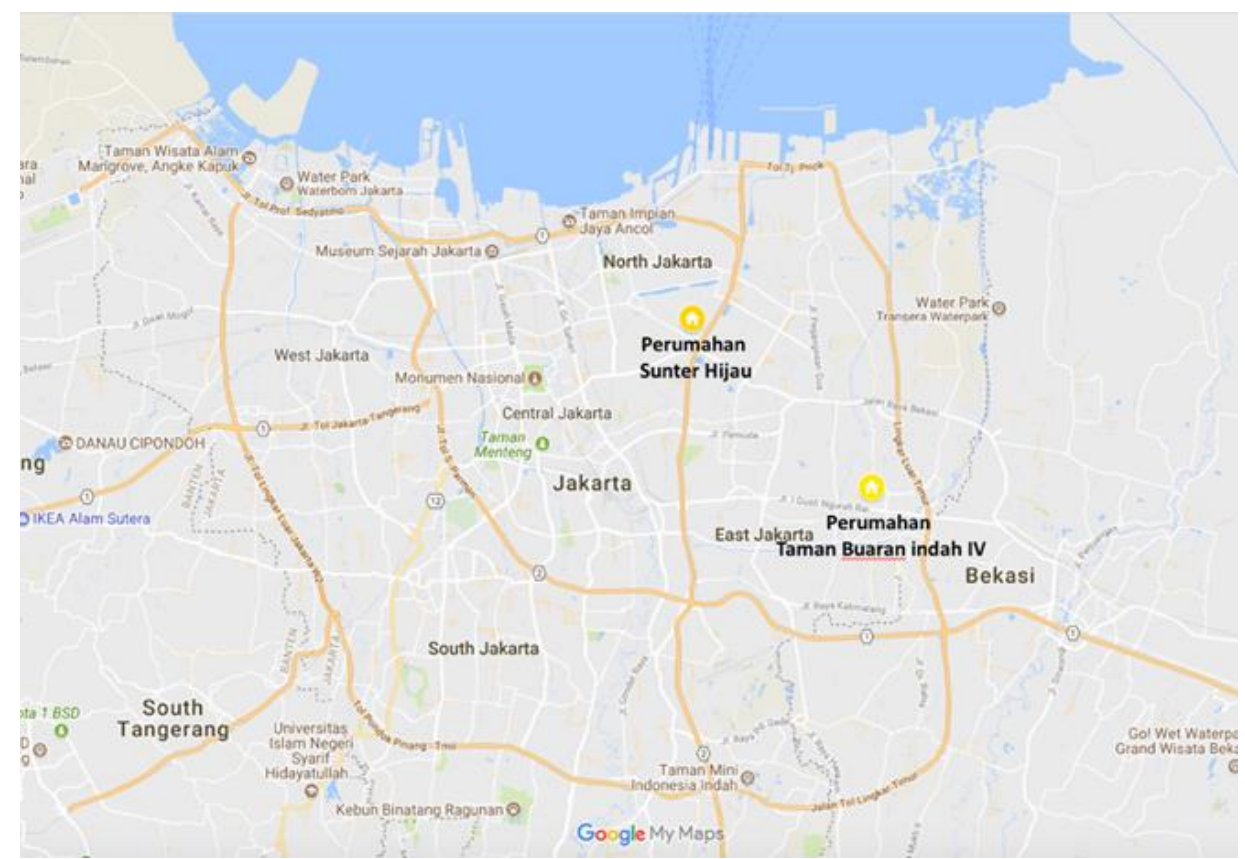

Gambar 1. Peta Ruang Lingkup Penelitian

Sumber : Pengolahan data pribadi

Jenis pekerjaan dan kegiatan dari para partisipan ini bervariasi, yaitu: 4 wiraswasta, 7 karyawan/karyawati swasta dan 2 mahasiswa (profesi mahasiswa dimasukan sebagai perbandingan dengan profesi lainnya, namun tetap memiliki rentang rutinitas perjalanan yang serupa). Sebagian besar telah menggunakan layanan Transjakarta untuk berangkat bekerja lebih dari 3 tahun, hanya 3 partisipan yang menggunakan layanan Transjakarta kurang dari 3 tahun terakhir ( 2 partisipan telah menggunakan selama 1 tahun dan 1 partisipan selama 2 tahun).

Tabel 1. Karakteristik Partisipan

\begin{tabular}{ccccc}
\hline Partisipan & $\begin{array}{c}\text { Jenis } \\
\text { Kelamin }\end{array}$ & $\begin{array}{c}\text { Usia } \\
\text { (tahun) }\end{array}$ & Pekerjaan & $\begin{array}{c}\text { Lama Menggunakan } \\
\text { Transjakarta }\end{array}$ \\
\hline P1 & Laki-laki & 67 & Wiraswasta & 6 tahun \\
\hline P2 & Perempuan & 38 & Karyawati Swasta & 4 tahun \\
\hline P3 & Perempuan & 39 & Karyawati Swasta & 3 tahun \\
\hline P4 & Perempuan & 24 & Karyawati Swasta & 4 tahun \\
\hline P5 & Laki-laki & 62 & Wiraswasta & 4 tahun \\
\hline
\end{tabular}




\begin{tabular}{ccccc}
\hline P6 & Perempuan & 35 & Karyawati Swasta & 2 tahun \\
\hline P7 & Laki-laki & 53 & Wiraswasta & 7 tahun \\
\hline P8 & Laki-laki & 31 & Karyawan Swasta & 1 tahun \\
\hline P9 & Perempuan & 44 & Karyawati Swasta & 11 tahun \\
\hline P10 & Perempuan & 19 & Mahasiswa & 1 tahun \\
\hline P11 & Laki-laki & 20 & Mahasiswa & 3 tahun \\
\hline P12 & Laki-laki & 30 & Wiraswasta & 10 tahun \\
\hline P13 & Laki-laki & 62 & Karyawan Swasta & 5 tahun \\
\hline & & Sumber : Pengolahan data pribadi
\end{tabular}

Gambaran hasil penelitian yang didapatkan dari para partisipan dalam penelitian ini :

- Pola Perjalanan Berangkat Kerja
$\checkmark$ Rincian Perjalanan Berangkat Kerja
$\checkmark$ Biaya Perjalanan Berangkat Kerja
$\checkmark$ Moda Split Berangkat Kerja
$\checkmark$ Trip Distribution

- Alasan Penggunaan Transjakarta

$\checkmark$ Murah

$\checkmark$ Lebih Nyaman dari Moda Transportasi Sebelumnya

$\checkmark$ Adanya Ajakan dari Pihak lain

$\checkmark$ Terdapatnya Keterbatasan pada Diri Pribadi

$\checkmark$ Terdapatnya Kesadaran Menggunakan Transportasi Umum dari Dalam Diri Pribadi

- Hambatan dan Tantangan Penggunaan Transjakarta

$\checkmark$ Masih Terbatasnya Jumlah Bus Pada Jam Kerja

$\checkmark$ Fasilitas Kendaraan yang Kurang Memenuhi Kebutuhan

$\checkmark$ Kendala di Fasilitas dan Infrastruktur Transjakarta Secara Keseluruhan

$\checkmark$ Kendala dari Faktor Luar Layanan Transportasi Transjakarta yang Mempengaruhi Kinerja Pelayanan dan Kepuasan para Penggunanya

- Penggunaan Kendaraan Pribadi Setelah Menggunakan Transjakarta Untuk Berangkat Bekerja

$\checkmark$ Penggunaan Sepeda Motor

$\checkmark$ Penggunaan Mobil

$\checkmark$ Transjakarta Belum Memenuhi Kebutuhan Berpergian Bersama Keluarga

- Penilaian Fasilitas dan Layanan Transjakarta Saat Ini

$\checkmark$ Bus

$\checkmark$ Halte

$\checkmark$ Pramuniaga

- Preferensi dan Harapan Untuk Transjakarta

$\checkmark$ Jumlah Unit Bus Diperbanyak

$\checkmark$ Perbaikan Kualitas Halte dan Sarana yang Telah Tersedia

$\checkmark$ Perbaikan atau Perubahan Infrastruktur, Sarana dan Prasarana

$\checkmark$ Perbaikan dan Peningkatan Sistim Layanan, Sistim Informasi layanan Transjakarta 
- Pendapat atau Keluhan dari Orang Lain yang Pernah Partisipan Dengar Dari Orang Lain

- Pola Perjalanan Pulang

$$
\begin{array}{ll}
\checkmark & \text { Rincian Perjalanan Pulang } \\
\checkmark & \text { Biaya Perjalanan Pulang } \\
\checkmark & \text { Moda Split Perjalanan Pulang }
\end{array}
$$

- Persentase Total Biaya Perjalanan Bulanan Terhadap Penghasilan

\begin{tabular}{|c|c|c|c|c|}
\hline Partisipan & $\begin{array}{l}\text { Moda } \\
\text { Awal }\end{array}$ & Transjakarta & $\begin{array}{l}\text { Moda } \\
\text { Akhir }\end{array}$ & $\begin{array}{c}\text { Total } \\
\text { Perjalanan }\end{array}$ \\
\hline P1 & $\begin{array}{c}\text { Motor pribadi } \\
\text { 1,5-2Km } \\
\text { Rp 7.000,- } \\
1-5 \text { Menit }\end{array}$ & $\begin{array}{c}\text { Walikota Jakarta Timur - Jatinegara RS. } \\
\text { Premier - Kampung Melayu } \\
\text { 12,8Km } \\
60-90 \text { Menit } \\
\text { Rp 0,- } \\
\end{array}$ & $\begin{array}{c}\text { Berjalan kaki } \\
\text { 250-500meter } \\
\text { Rp 0,- } \\
\text { 5-10 Menit }\end{array}$ & $\begin{array}{c}15 \mathrm{Km} \\
\text { Rp 7.000,- } \\
60-90 \text { Menit }\end{array}$ \\
\hline $\mathrm{P} 2$ & $\begin{array}{c}\text { Diantar Motor } \\
\text { 250-500meter } \\
\text { Rp 0,- } \\
\text { 1-5 Menit }\end{array}$ & $\begin{array}{c}\text { Simpang Tiga }- \text { Walikota Jakarta Timur }- \text { ST. } \\
\text { Jatinegara }- \text { Permai Koja } \\
24,2 \mathrm{Km} \\
60-90 \text { Menit } \\
\text { Rp 2.000,- } \\
\end{array}$ & $\begin{array}{c}\text { Berjalan kaki } \\
\text { 250-500meter } \\
\text { Rp 0,- } \\
\text { 5-10 Menit }\end{array}$ & $\begin{array}{c}25 \mathrm{Km} \\
\text { Rp 2.000,- } \\
90-120 \text { Menit }\end{array}$ \\
\hline P3 & $\begin{array}{c}\text { Berjalan kaki } \\
\text { 250-500meter } \\
\text { Rp 0,- } \\
\text { 1-5 Menit }\end{array}$ & $\begin{array}{c}\text { Simpang Tiga - Walikota Jakarta Timur - ST. } \\
\text { Jatinegara - Cawang Uki - Kuningan Barat - } \\
\text { Departemen Kesehatan } \\
21,6 \mathrm{Km} \\
60-90 \text { Menit } \\
\text { Rp 2.000,- }\end{array}$ & $\begin{array}{c}\text { Berjalan kaki } \\
0-250 \text { meter } \\
\text { Rp 0,- } \\
\text { 1-5 Menit }\end{array}$ & $\begin{array}{c}22 \mathrm{Km} \\
\text { Rp 2.000,- } \\
90-120 \text { Menit }\end{array}$ \\
\hline P4 & $\begin{array}{c}\text { Berjalan kaki } \\
\text { 500-750meter } \\
\text { Rp 0,- } \\
\text { 5-10 Menit }\end{array}$ & $\begin{array}{c}\text { Simpang Tiga - } \\
\text { Pulogadung }- \text { Dukuh Atas - GOR Sumantri } \\
\text { 22,7Km } \\
\text { 60-90Menit } \\
\text { Rp 5.500,-- } \\
\end{array}$ & $\begin{array}{c}\text { Berjalan kaki } \\
\text { 250-500meter } \\
\text { Rp 0,- } \\
\text { 0-5 Menit }\end{array}$ & $\begin{array}{c}23 \mathrm{Km} \\
\text { Rp 5.500,- } \\
\text { 90-120 Menit }\end{array}$ \\
\hline P5 & $\begin{array}{c}\text { Berjalan kaki } \\
0-250 \text { meter } \\
\text { Rp 0,- } \\
\text { 1-5 Menit }\end{array}$ & $\begin{array}{c}\text { Simpang Tiga - } \\
\text { Walikota Jakarta Timur - ST. Jatinegara - } \\
\text { PGC } \\
\text { 17,2Km } \\
\text { 45-60Menit } \\
\text { Rp 3.500,- }\end{array}$ & $\begin{array}{c}\text { Berjalan kaki } \\
\text { 250-500meter } \\
\text { Rp 0,- } \\
\text { 1-5 Menit }\end{array}$ & $\begin{array}{c}18 \mathrm{Km} \\
\text { Rp 3.500,- } \\
\text { 60-90 Menit }\end{array}$ \\
\hline P6 & $\begin{array}{c}\text { Berjalan kaki } \\
\text { 250-500meter } \\
\text { Rp 0,- } \\
\text { 1-5 Menit }\end{array}$ & $\begin{array}{c}\text { Simpang Tiga - } \\
\text { Walikota Jakarta Timur - } \\
\text { Kampung Melayu - } \\
\text { UI Salemba } \\
\text { 15,3Km } \\
60-90 \mathrm{Menit} \\
\text { Rp 3.500,-- }\end{array}$ & $\begin{array}{c}\text { Berjalan kaki } \\
0-250 \text { meter } \\
\text { Rp 0,- } \\
\text { 1-5 Menit }\end{array}$ & $\begin{array}{c}16 \mathrm{Km} \\
\text { Rp 3.500,- } \\
60-90 \text { Menit }\end{array}$ \\
\hline P7 & $\begin{array}{c}\text { Berjalan kaki } \\
\text { 250-500meter } \\
\text { Rp 0,- } \\
\text { 5-10 Menit }\end{array}$ & $\begin{array}{c}\text { Simpang Tiga - } \\
\text { Pulogadung - } \\
\text { Pasar Senen - } \\
\text { Mangga Dua Square - } \\
\text { ITC Mangga Dua }\end{array}$ & $\begin{array}{l}\text { Berjalan kaki } \\
\text { 0-250meter } \\
\text { Rp 0,- } \\
\text { 1-5 Menit }\end{array}$ & $\begin{array}{c}21 \mathrm{Km} \\
\text { Rp 7.000,- } \\
90-120 \text { Menit }\end{array}$ \\
\hline
\end{tabular}

\section{Pola Perjalanan Berangkat Kerja}

Tabel 2. Pola Perjalanan Berangkat Kerja 


\begin{tabular}{|c|c|c|c|c|}
\hline & & $\begin{array}{c}20,6 \mathrm{Km} \\
\text { 60-90Menit } \\
\text { Rp 7.000,- }\end{array}$ & & \\
\hline P8 & $\begin{array}{l}\text { Ojek online } \\
\text { 3,4Km } \\
\text { Rp 7.000,- } \\
\text { 5-10Menit }\end{array}$ & $\begin{array}{c}\text { Cempaka Timur - } \\
\text { Harmoni Central Busway - } \\
\text { Bundaran Senayan } \\
\text { 14,6Km } \\
\text { 60-90Menit } \\
\text { Rp 3.500,- }\end{array}$ & $\begin{array}{l}\text { Ojek online } \\
\text { 3,4Km } \\
\text { Rp 9.000,- } \\
\text { 5-10Menit }\end{array}$ & $\begin{array}{c}22 \mathrm{Km} \\
\text { Rp 19.500,- } \\
90-120 \text { Menit }\end{array}$ \\
\hline P9 & $\begin{array}{l}\text { Ojek online } \\
2,8 \mathrm{Km} \\
\text { Rp 8.000,- } \\
\text { 5-10Menit }\end{array}$ & $\begin{array}{c}\text { Cempaka Timur - } \\
\text { Harmoni Central Busway - } \\
\text { Karet Sudirman } \\
\text { 15,6Km } \\
\text { 60-90Menit } \\
\text { Rp 2.000,- }\end{array}$ & $\begin{array}{c}\text { Berjalan kaki } \\
\text { 250-500meter } \\
\text { Rp 0,- } \\
\text { 0-5Menit }\end{array}$ & $\begin{array}{c}19 \mathrm{Km} \\
\mathrm{Rp} 10.000,- \\
90-120 \text { Menit }\end{array}$ \\
\hline P10 & $\begin{array}{l}\text { Ojek online } \\
\text { 2,6Km } \\
\text { Rp 7.000,- } \\
\text { 5-10Menit }\end{array}$ & $\begin{array}{c}\text { Cempaka Timur - } \\
\text { Harmoni Central Busway - } \\
\text { Blok M - } \\
\text { Kodam Bintaro } \\
\text { 33,6Km } \\
\text { 90-120Menit } \\
\text { Rp 2.000,- }\end{array}$ & $\begin{array}{l}\text { Ojek online } \\
\quad 8 \mathrm{Km} \\
\text { Rp 20.000,- } \\
\text { 15-20Menit }\end{array}$ & $\begin{array}{c}44 \mathrm{Km} \\
\text { Rp 29.000,- } \\
\text { 120-150 Menit }\end{array}$ \\
\hline P11 & $\begin{array}{l}\text { Ojek online } \\
2,8 \mathrm{Km} \\
\text { Rp 7.500,- } \\
5-10 \mathrm{Menit}\end{array}$ & $\begin{array}{c}\text { Cempaka Timur - } \\
\text { Harmoni Central Busway - } \\
\text { Bendungan Hilir } \\
\text { 14,8Km } \\
\text { 60-90Menit } \\
\text { Rp 2.000,- }\end{array}$ & $\begin{array}{c}\text { Berjalan kaki } \\
0-250 \text { meter } \\
\text { Rp 0,- } \\
\text { 1-5Menit }\end{array}$ & $\begin{array}{c}18 \mathrm{Km} \\
\mathrm{Rp} 12.000,- \\
90-105 \text { Menit }\end{array}$ \\
\hline P12 & $\begin{array}{c}\text { Berjalan kaki } \\
2,2 \mathrm{Km} \\
\mathrm{Rp} \mathrm{0,-} \\
\text { 15-20Menit }\end{array}$ & $\begin{array}{c}\text { Cempaka Timur - } \\
\text { Harmoni Central Busway - } \\
\text { Tosari ICBC } \\
\text { 10,3Km } \\
\text { 45-60Menit } \\
\text { Rp 3.500,- }\end{array}$ & $\begin{array}{c}\text { Berjalan kaki } \\
\text { 250-500meter } \\
\text { Rp 0,- } \\
\text { 1-5Menit }\end{array}$ & $\begin{array}{c}13 \mathrm{Km} \\
\text { Rp 3.500,- } \\
\text { 60-90 Menit }\end{array}$ \\
\hline P13 & $\begin{array}{c}\text { Motor pribadi } \\
2,6 \mathrm{Km} \\
\text { Rp } 10.000,- \\
1-5 \mathrm{Menit}\end{array}$ & $\begin{array}{c}\text { Cempaka Timur - } \\
\text { Harmoni Central Busway - } \\
\text { Kalideres } \\
\text { 24,2Km } \\
\text { 90-120Menit } \\
\text { Rp 3.500,- }\end{array}$ & $\begin{array}{c}\text { Berjalan kaki } \\
\text { 250-500meter } \\
\text { Rp 0,- } \\
\text { 1-5Menit }\end{array}$ & $\begin{array}{c}27 \mathrm{Km} \\
\mathrm{Rp} 13.500,- \\
90-120 \text { Menit }\end{array}$ \\
\hline
\end{tabular}

Sumber : Pengolahan data pribadi

Pada hasil pembahasan dapat disimpulkan bahwa Jarak perjalanan dari rumah ke tempat bekerja dengan menggunakan layanan Transjakarta minimum berjarak $13 \mathrm{~km}$ dan maksimum $44 \mathrm{~km}$ dengan kesimpulan bahwa jarak perjalanan termasuk dalam jangkauan jauh. Waktu tempuh perjalanan dari rumah ke tempat bekerja dengan menggunakan layanan Transjakarta paling minimum berdurasi 60-90 menit dan maksimum 120-150 menit dengan kesimpulan bahwa durasi waktu perjalanan masih sangat jauh dari kondisi ideal dan bilamana dirincikan menjadi kecepatan jelajah rata-rata adalah $>20 \mathrm{~km} / \mathrm{jam}$. Moda split pada kedua lokasi terdapat 3 (tiga) moda (moda awal - Transjakarta - moda akhir), pada moda awal masing-masing lokasi terdapat 2 (dua) jenis moda yang digunakan, yaitu: 1) sepeda motor dan 2) berjalan kaki, namun pada lokasi objek studi trip generator terdapat perbedaan jumlah komposisi. Hal tersebut terlihat berdasarkan komposisi penggunaan moda split yang didapatkan, dapat disimpulkan bahwa jarak 
halte transjakarta terdekat dengan trip generator memberikan andil pemilihan moda transportasi yang dirasa efisien dan efektif oleh para masing-masing partisipan. Diketahui juga tidak terdapatnya fasilitas parkir kendaraan pribadi (Halte Transjakarta tidak mendukung sistim park and ride) memberikan opsi penggunaan transportasi ojek online daripada menggunakan kendaraan pribadi berupa sepeda, sepeda motor atau mobil. Sebagai analisis keseluruhan hasil penelitian moda split (moda awal dan moda akhir) dapat ditarik kesimpulan bahwa mayoritas para partisipan pengguna layanan Transjakarta untuk berangkat bekerja akan lebih memilih untuk menggunakan moda berjalan kaki bilamana jaraknya masih dapat ditempuh dengan berjalan kaki, dalam kasus ini yang memilih menggunakan moda transportasi berjalan kaki memiliki jarak $\leq 500$ meter, sedangkan partisipan yang memilih menggunakan moda sepeda motor memiliki jarak dari halte terdekat ke tempat bekerja atau tempat belajar lebih dari $\leq 500$ meter $(3,4 \mathrm{~km}$ dan $8 \mathrm{~km})$. Trip distribution dari kedua objek lokasi trip generator (perumahan Sunter Hijau dan perumahan Taman Buaran Indah IV) ke masing-masing tempat bekerja (trip attractor) sangat bervariasi, namun dari masing-masing trip generator (perumahan Sunter Hijau dan perumahan Taman Buaran Indah IV) terdapat satu trip attractor yang paling banyak dituju. Wilayah tersebut adalah Kota Administrasi Jakarta Selatan yang menjadi trip attractor yang terbanyak, sebanyak 6 (enam) partisipan bekerja di wilayah administrasi tersebut (di wilayah ruas Jalan Jendral Sudirman dan Jalan Rasuna Said banyak terdapat gedung perkantoran serta pusat perdagangan dan jasa).

\section{Alasan Penggunaan Transjakarta}

Terdapat berbagai macam alasan menggunakan layanan BRT Transjakarta untuk berangkat bekerja: 1) Murah, salah satu alasan menggunakan layanan Transjakarta dikarenakan berbiaya murah sehingga dapat didefinisikan salah satu value point dari layanan Transjakarta adalah "murah". 2)Salah satu value point lainnya dari layanan Transjakarta adalah "layanan Transjakarta lebih nyaman daripada moda layanan transportasi sebelumnya”. 3)Adanya ajakan dari pihak lain dapat didefinisikan bahwa perilaku menggunakan layanan Transjakarta dapat ditularkan kepada masyarakat lain yang belum menggunakan layanan Transjakarta untuk berangkat bekerja, "ajakan dari pihak lain" dapat menjadi salah satu strong point untuk menggunakan layanan Transjakarta untuk berangkat bekerja. 4)Salah satu alasan bahwa terdapatnya keterbatasan dalam diri pribadi memicu penggunaan Transjakarta untuk berangkat bekerja, hal ini dapat didefinisikan dengan adanya layanan Transjakarta juga memberikan solusi atas alasan "terdapatnya keterbatasan dalam diri pribadi". 5)Terdapatnya kesadaran dalam menggunakan transportasi umum dari dalam diri pribadi, dari alasan tersebut memberikan gambaran bahwa masyarakat Kota Jakarta sudah mulai sadar akan penggunaan transportasi umum untuk berangkat bekerja

\section{Hambatan dan Tantangan Penggunaan Transjakarta}

Dalam hasil penelitian bagian hambatan dan tantangan penggunaan transjakarta terdapat beberapa kendala yang ditemukan, seperti: 1) "masih terbatasnya jumlah bus, lamanya waktu tunggu dan terbatasnya kapasitas angkutan" memberikan gambaran bahwa masih terdapatnya kesulitan para partisipan menggunakan moda layanan Transjakarta dengan waktu yang efisien 
yang disebabkan oleh alasan di atas. 2) "fasilitas kendaraan yang kurang memenuhi kebutuhan" memberikan gambaran bahwa diperlukannya perhatian lebih untuk memenuhi kebutuhan para pengguna layanan Transjakarta pada saat berangkat bekerja. 3)"kendala di fasilitas dan infrastruktur Transjakarta secara keseluruhan dan kendala dalam sistim informasi layanan Transjakarta". Diketahui hal ini memberikan gambaran bahwa terdapatnya kendala mengakses serta kesulitan dalam penggunaan fasilitas dan infrastruktur Transjakarta, seperti jembatan terlalu tinggi dan harus berjalan jauh untuk mengaksesnya, menggunakan material yang dirasakan kurang solid juga dirasakan cukup mempengaruhi penggunaan layanan Transjakarta dalam berangkat bekerja, juga terdapat kendala dalam sistim informasi layanan transjakarta terutama mengenai info kedatangan ETA (estimation time arrival) bus yang sangat berpengaruh pada kenyamanan para penumpang. Dikarenakan berangkat bekerja memerlukan perhitungan waktu yang cermat dan tidak jarang mereka berlomba dengan waktu tersebut. 4) "kendala dari faktor luar layanan transportasi Transjakarta yang mempengaruhi kinerja pelayanan dan kepuasan para penggunanya", hal ini memberikan petunjuk mengenai terdapatnya faktor-faktor luar layanan Transjakarta yang banyak mempengaruhi perjalanan berangkat bekerja, dan hal ini memberikan situasi yang kurang kondusif sehingga diperlukan solusi untuk penyelesaiannya guna menciptakan perjalanan berangkat bekerja yang lebih nyaman dan waktu yang efisien.

\section{Penggunaan Kendaraan Pribadi Setelah Menggunakan Layanan Transjakarta untuk Berangkat Bekerja}

Layanan Transjakarta memberikan kontribusi positif terhadap penggunaan moda transportasi sepeda motor yang digunakan hanya untuk jarak yang relative dekat $(\leq 5 \mathrm{Km})$, dan hal ini memberikan kontribusi positif terhadap pencegahan terjadinya kecelakan bermotor jenis transportasi sepeda motor di jalanan. Layanan Transjakarta belum dapat memenuhi kebutuhan berpergian bersama keluarga, namun diketahui juga partisipan menyatakan bahwa "layanan Transjakarta belum memenuhi kebutuhan berpergian bersama keluarga" dikarenakan berbagai alasan tertentu (sarana dan prasarana didalam dan diluar bus, serta infrastruktur penunjang seperti jembatan yg sulit diakses dan cenderung tidak nyaman memberikan andil besar atas pembentukan kesimpulan tersebut) sehingga layanan Transjakarta dianggap masih belum memenuhi kebutuhan untuk bepergian bersama keluarga sehingga pilihannya adalah tetap menggunakan kendaraan pribadi.

\section{Penilaian Fasilitas dan Layanan Transjakarta Saat Ini}

Dalam penelitian bagian ini dilakukan penilaian kualitas fasilitas dan layanan Transjakarta menurut pendapat pribadi para partisipan dengan rentang nilai 1 s/d 10, dimana semakin besar nilai mempresentasikan kualitas yang semakin baik.

Tabel 3. Penilaian Fasilitas dan Layanan Transjakarta oleh Partisipan

\begin{tabular}{ccccccccccccccc}
\hline & P1 & P2 & P3 & P4 & P5 & P6 & P7 & P8 & P9 & P10 & P11 & P12 & P13 & Median \\
\hline BusKecil & - & - & 5 & 5 & - & 5 & 6 & - & - & - & - & - & - & 5,25 \\
\hline Bus Besar & 9 & 8 & 8 & 8 & 7 & 7 & 8 & 8 & 7 & 8 & 7,5 & 8 & 8 & 7,80 \\
\hline Bus Scania & 9 & 8 & 8 & 8 & 7 & 7 & 8 & 8 & 8 & 8 & 7,5 & 8 & 8 & 7,88 \\
\hline
\end{tabular}




\begin{tabular}{ccccccccccccccc}
\hline Halte & 8 & 7 & 7 & 7 & 5 & 7 & 7 & 7 & 7 & 8 & 6 & 6 & 6 & 6,76 \\
\hline Pramuniaga & 8 & 8 & 7 & 8,5 & 8 & 8 & 9 & 8 & 7 & 7 & 8 & 8 & 8 & 7,88 \\
\hline
\end{tabular}

Sumber : Pengolahan data pribadi

Dari keseluruhan hasil penelitian dan wawancara yang di dapatkan perihal penilaian fasilitas dan layanan Transjakarta saat ini, dapat disimpulkan bahwa: Penilaian bus kecil menurut para partisipan masih kurang baik, hal ini dapat dilihat dari hasil pemberian skor oleh para partisipan yang berada pada skor 5-6 dengan nilai skor rata-rata sebesar 5,25. Penilaian bus besar menurut para partisipan berada dalam level baik, hal ini dapat dilihat dari hasil pemberian skor oleh para partisipan yang berada pada skor 7-9 dengan nilai skor rata-rata sebesar 7,80. Penilaian bus Scania menurut para partisipan berada dalam level baik, hal ini ditunjukan dari hasil pemberian skor oleh masing-masing partisipan yang berada pada skor 7-9 dengan nilai skor rata-rata sebesar 7,88. Penilaian fasilitas halte Transjakarta oleh para partisipan dapat disimpulkan berada pada level cukup baik, hal ini ditunjukan dari hasil pemberian skor oleh masing-masing partisipan yang berada pada skor 5-8 dengan nilai skor rata-rata sebesar 6,76. Penilaian fasilitas halte Transjakarta oleh para partisipan dapat disimpulkan berada pada level cukup baik, hal ini ditunjukan dari hasil pemberian skor oleh masing-masing partisipan yang berada pada skor 5-8 dengan nilai skor rata-rata sebesar 6,76. Penilaian pelayanan Transjakarta oleh pramuniaga baik yang berada di dalam bus maupun yang berada di setiap halte, oleh masing-masing partisipan disimpulkan berada di level baik, hal ini ditunjukan dari hasil pemberian skor oleh masingmasing partisipan yang berada pada skor 7-9 dengan nilai skor rata-rata sebesar 7,88.

\section{Preferensi dan Harapan untuk Transjakarta}

Berbagai macam preferensi dan harapan untuk BRT Transjakarta adalah: 1) "preferensi dan harapan agar jumlah unit bus diperbanyak”. Hal ini cukup memberikan korelasi yang kuat dari bagian hambatan dan tantangan yang didapatkan dalam menggunakan layanan Transjakarta berangkat bekerja tentang adanya keterbatasan jumlah bus, lamanya waktu tunggu dan terbatasnya kapasitas angkutan. 2) "preferensi dan harapan untuk perbaikan kualitas halte dan sarana Transjakarta yang telah tersedia". Hal ini juga cukup memberikan korelasi yang kuat dari hambatan dan tantangan yang di dapatkan dalam menggunakan layanan Transjakarta berangkat bekerja, dimana pengguna layanan Transjakarta menilai masih minimnya kualitas dan sarana Transjakarta yang telah tersedia. 3) "preferensi dan harapan agar adanya perbaikan atau perubahan infrastruktur, sarana dan prasarana Transjakarta". Hal ini memberikan gambaran yang dirasakan kurang atau tidak tepatnya rancangan infrastruktur sarana dan prasarana Transjakarta bagi para penggunanya sehingga mengurangi kenyamanan para pengguna layanan Transjakarta untuk berangkat bekerja. 4) "preferensi dan harapan tentang perbaikan dan peningkatan sistim layanan, sistim informasi Transjakarta”. Hal ini juga memberikan korelasi keterkaitan antara hambatan dan tantangan dalam menggunakan layanan Transjakarta untuk berangkat bekerja bagian kendala dalam layanan sistim informasi layanan Transjakarta, dan juga adanya harapan perbaikan dan peningkatan sistim layanan, sistim informasi yang bertujuan agar dapat memberikan estimasi waktu yang tepat dalam pemilihan moda transportasi untuk berangkat bekerja. 


\section{Pendapat atau Keluhan yang Pernah Partisipan Dengar Tentang Transjakarta dari Pihak lain}

Pendapat atau keluhan yang pernah partisipan dengan tentang Transjakarta dari pihak lain menjabarkan keseluruhan pendapat atau keluhan yang partisipan pernah dengar tentang Transjakarta dari pihak lain, dimana terdapat 1 (satu) pendapat bahwa perlunya toleransi dalam menggunakan layanan transportasi umum haruslah tinggi, lalu terdapat 4 (empat) keluhan yang partisipan pernah dengar tentang Transjakarta dari pihak lain, yaitu : keluhan tentang jumlah unit bus yang kurang dan waktu kedatangan bus yang lama, keluhan tentang tempat duduk di dalam bus yang jauh lebih sedikit dari kapasitas tampung penumpang, keluhan tentang kurang sigapnya pramuniaga dalam melayani kebutuhan penumpang, keluhan tentang adanya titik-titik kerawanan keamanan dalam koridor wilayah sarana dan prasarana layanan Transjakarta.

Tiga dari empat keluhan tersebut memiliki kemiripan dengan hambatan dan tantangan yang dialami oleh partisipan dalam berangkat bekerja, dan hanya satu temuan keluhan baru yang berhubungan dengan masalah keamanan dan tingkat kerawanan di titik-titik tertentu.

\section{Pola Perjalanan Pulang}

Pada penelitian pola perjalanan pulang ini ditemukan seluruh partisipan juga menggunakan layanan Transjakarta untuk menempuh tempat hunian mereka masing-masing, ditemukan bahwa alasan para partisipan kembali menggunakan layanan Transjakarta karena layanan ini termasuk salah satu layanan yang memiliki konsistensi yang baik dan dapat diandalkan dalam perjalanan berangkat maupun pulang bekerja. Berikut gambaran pola perjalanan pulang: 1)Jarak perjalanan dan waktu tempuh perjalanan pola perjalanan pulang tidak jauh berbeda dengan pola berangkat, dikarenakan para partisipan relatif menggunakan koridor jalur yang sama pada saat pulang dan berangkat bekerja, diketahui juga waktu tempuh perjalanan pada waktu pagi dan sore/malam relatif sama yang mungkin disebabkan oleh tingkat lalu lintas pada pagi dan sore/malam hari identik tidak memiliki perbedaan yang jauh beragam. 2)Moda split pada pola perjalanan pulang dari tempat bekerja ke rumah sama-sama memiliki tiga (3) moda (moda awal - Transjakarta moda akhir), namun pada moda akhir masing-masing lokasi terdapat perbedaan jumlah komposisi. Hal tersebut terlihat pada persentase yang menggunakan sepeda motor pada moda akhir di lokasi objek studi trip generator 1 (perumahan Sunter Hijau) memiliki komposisi lebih besar menggunakan sepeda motor yang disebabkan oleh jarak antara halte Transjakarta terdekat dengan tempat tujuan relatif tidak dapat dijangkau dengan berjalan kaki. Sedangkan pada moda akhir di lokasi objek studi trip generator 2 (perumahan Taman Buaran Indah IV) komposisi yang lebih besar adalah moda akhir yang menggunakan moda jalan kaki dibandingkan dengan moda sepeda motor. Namun perlu diketahui juga bahwa terdapatnya perubahan pola pada moda akhir, dimana pada trip generator 2 (perumahan Taman Buaran Indah IV) diketahui moda akhir menuju rumah dengan berjalan kaki meningkat dikarenakan jarak halte terakhir memiliki jarak yang masih dapat dijangkau dengan berjalan kaki ( $\leq 500$ meter).

\section{Total Keseluruhan Biaya Perjalanan Bulanan Dibandingkan dengan Penghasilan}

Pada bagian ini dijelaskan menjabarkan total keseluruhan biaya perjalanan bulanan dibandingkan dengan penghasilan dari masing-masing total biaya perjalanan para partisipan, dimana penghasilan sebagai alat pembanding dikategorikan menjadi 2 (dua) jenis yaitu: pendapatan UMR (upah minimum regional) dan pendapatan pribadi masing-masing partisipan. 
Tabel 4. Total Keseluruhan Biaya Perjalanan Bulanan Dibandingkan dengan Penghasilan

\begin{tabular}{|c|c|c|c|}
\hline Partisipan & $\begin{array}{c}\text { Biaya Perjalanan per } \\
\text { Bulan }\end{array}$ & Penghasilan UMR & $\begin{array}{c}\text { Penghasilan } \\
\text { Pribadi }\end{array}$ \\
\hline P1 & Rp 140.000,- & $0-5 \%$ & $0-5 \%$ \\
\hline $\mathrm{P} 2$ & Rp 110.000,- & $0-5 \%$ & $0-5 \%$ \\
\hline $\mathrm{P} 3$ & Rp 110.000,- & $0-5 \%$ & $0-5 \%$ \\
\hline $\mathrm{P} 4$ & Rp 250.000,- & $5-10 \%$ & $0-5 \%$ \\
\hline P5 & Rp 140.000,- & $0-5 \%$ & $0-5 \%$ \\
\hline P6 & Rp 140.000,- & $0-5 \%$ & $0-5 \%$ \\
\hline P7 & Rp 280.000,- & $5-10 \%$ & $0-5 \%$ \\
\hline P8 & Rp 780.000,- & $20-25 \%$ & $5-10 \%$ \\
\hline P9 & $\operatorname{Rp} 430.000,-$ & $10-15 \%$ & $5-10 \%$ \\
\hline $\mathrm{P} 10$ & Rp 1.190.000,- & $30-35 \%$ & - \\
\hline P11 & Rp 460.000,- & $10-15 \%$ & - \\
\hline $\mathrm{P} 12$ & Rp 140.000,- & $0-5 \%$ & $0-5 \%$ \\
\hline P13 & Rp 540.000,- & $10-15 \%$ & $5-10 \%$ \\
\hline
\end{tabular}

Sumber : Pengolahan data pribadi

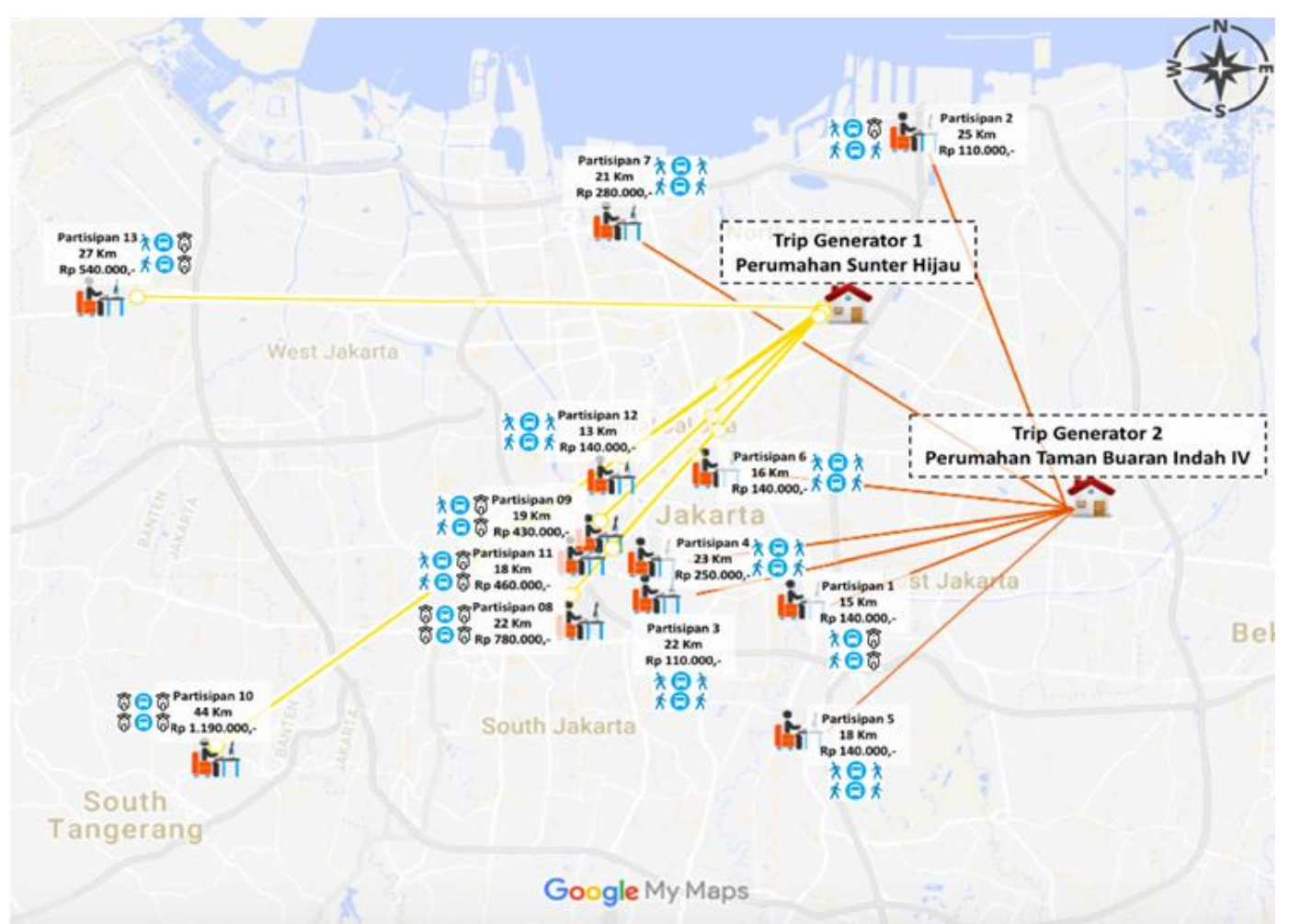

Gambar 2. Peta Pola Perjalanan Para Partisipan 1-13 beserta dengan pola moda Sumber : Pengolahan data pribadi

Dari keseluruhan hasil penelitian diatas, dapat disimpulkan: biaya perjalanan minimum per bulan. Rp 110.000,- dan maksimum Rp 1.190.000,-, Biaya perjalanan minimum per bulan dibandingkan dengan penghasilan UMR sebesar 0-5 \% dan maksimum sebesar 30-35\%, biaya perjalanan minimum per bulan dibandingkan dengan penghasilan pribadi sebesar 0-5 \% dan maksimum sebesar 5-10\%. Dari penjabaran diatas dapat disimpulkan bahwa pada partisipan $1 \mathrm{~s} / \mathrm{d} 7$ yang berada di lokasi trip generator 2 (perumahan Taman Buaran Indah IV) memiliki total keseluruhan biaya perjalanan bulanan lebih murah dibandingkan dengan partisipan 8 s/d 13 yang berada di lokasi trip generator 1 (perumahan 
Sunter Hijau) hal ini terjadi dikarenakan terdapatnya perbedaan jarak rumah dengan halte Transjakarta terdekat yang menyebabkan terjadinya perbedaan kemudahan penjangkauan halte Transjakarta terdekat sehingga berimbas pada perbedaan penggunaan moda transportasi untuk menjangkau halte Transjakarta tersebut.

\section{Perbandingan dan Perbedaan}

Dalam bagian ini dicantumkan beberapa penelitian, baik yang berasal dari jurnal penelitian internasional maupun laporan resmi dari badan transportasi daerah yang memiliki sistim layanan transportasi berbentuk BRT (Bus Rapid Transit) untuk melayani kebutuhan mobilitas para penduduk perkotaan, baik berangkat bekerja maupun kebutuhan lainnya. Tujuan disajikannya bab ini adalah sebagai upaya untuk memperkaya hasil penelitian, baik dalam pembelajaran halhal yang berhasil maupun hal-hal yang dianggap kurang berhasil dari temuan-temuan penelitian tersebut. Berikut dicantumkan penelitian tersebut beserta dengan perbandingan dan perbedaannya dengan layanan BRT Transjakarta:

1) Mairead Cantwell, Brian Caulfield, Margareth O'Mahony, Examining The Factors That Impact Public Transport Commuting Satisfaction, 2009. ISSN : 1077-291X.

2) Heather Allen, Bus Reform in Seoul, Republic of Korea. Case study prepared for the Global Report on Human Settlements, 2013.

3) Taotao Deng, Mulan Ma, and Jing Wang, Evaluation of Bus Rapid Transit Implementation in China : Current Performance and Progress, 2013. DOI: 10.1061/(ASCE)UP.1943-5444.0000150. American Society of Civil Engineers

4) Federal Transit Administration Research, Metro Orange Line BRT Project Evaluation, 2011. Los Angeles. FTA Report No. 0004, Federal Transit Administration.

5) Fabio Duarte, Fernando Rojas \& D. Hidalgo, Intermodal Connectivity to BRT : A Comparative Analysis of Bogota and Curitiba, 2012. Bogota. \& Transmilenio:A High Capacity - Low Cost Bus Rapid Transit System Developed for Bogota, Colombia.

Tabel 5. Perbandingan dan Perbedaan BRT System

\begin{tabular}{|c|c|c|c|c|c|c|}
\hline & $\begin{array}{c}\text { DART } \\
\text { (Dublin Bus, } \\
\text { Irlandia) } \\
\end{array}$ & $\begin{array}{c}\text { SMRT } \\
\text { (Seoul BRT, } \\
\text { Korea) } \\
\end{array}$ & $\begin{array}{c}\text { Beijing BRT } \\
\text { (Beijing, China) }\end{array}$ & $\begin{array}{c}\text { Orange Line } \\
\text { (Los Angeles, } \\
\text { USA) } \\
\end{array}$ & $\begin{array}{c}\text { Transmilenio } \\
\text { (Bogota, } \\
\text { Colombia) }\end{array}$ & $\begin{array}{c}\text { Transjakarta } \\
\text { (Jakarta, } \\
\text { Indonesia) } \\
\end{array}$ \\
\hline $\begin{array}{c}\text { Transportasi } \\
\text { Publik } \\
\text { yang Tersedia }\end{array}$ & $\begin{array}{ll}- & \text { Metro Train } \\
- & \text { Dublin Bus } \\
- & \text { LUAS Tram }\end{array}$ & $\begin{array}{l}\text { Metro } \\
\text { Subway } \\
\text { SMRT Bus }\end{array}$ & $\begin{array}{ll}- & \text { MRT } \\
- & \text { LRT } \\
- & \text { BRT }\end{array}$ & $\begin{array}{ll}- & \text { MRT } \\
- & \text { Commuter } \\
& \text { Train } \\
- & \text { Orange Line }\end{array}$ & Transmilenio & Transjakarta \\
\hline Moda Split & $\begin{array}{r}\text { Jalan kaki atau bers } \\
\text { dengan } \mathrm{m}\end{array}$ & $\begin{array}{l}\text { eda, diteruskan de } \\
\text { transportasi utam }\end{array}$ & $\begin{array}{l}\text { moda transporta } \\
\text { diakhiri dengan }\end{array}$ & $\begin{array}{l}\text { T dan dilanjutkan } \\
\text { alan kaki }\end{array}$ & $\begin{array}{c}\text { Jalan kaki atau } \\
\text { bersepeda } \\
\text { diteruskan dengan } \\
\text { moda transportasi } \\
\text { BRT dan diakhiri } \\
\text { dengan berjalan } \\
\text { kaki }\end{array}$ & $\begin{array}{c}\text { Jalan kaki atau } \\
\text { sepeda motor } \\
\text { (ojek online) } \\
\text { diteruskan dengan } \\
\text { moda transportasi } \\
\text { BRT dan diakhiri } \\
\text { dengan berjalan } \\
\text { kaki atau sepeda } \\
\text { motor (ojek } \\
\text { online) }\end{array}$ \\
\hline $\begin{array}{c}\text { Tujuan } \\
\text { Penggunan } \\
\text { Layanan BRT ke } \\
\text { Tempat Kerja } \\
\end{array}$ & \multicolumn{6}{|c|}{$\begin{array}{r}\text { Dikarenakan transportasi pribadi sudah tidak dapat digunakan lagi sebagai moda tra } \\
\text { bekerja, penyebabnya adalah efek dari semakin bertambahnya jumlah penduduk dan } \\
\text { moda transportasi yang berada di atasnya. }\end{array}$} \\
\hline $\begin{array}{c}\text { Implikasi dan } \\
\text { Data Lapangan }\end{array}$ & $\begin{array}{l}\text { Waktu perjalanan } \\
\text { menggunakan } \\
\text { transportasi } \\
\text { umum menjadi } \\
\text { lebih lama dari } \\
\text { yang sebelumnya } \\
\text { 51\% pengguna } \\
\text { Dublin Bus } \\
\text { berangkat kerja } \\
\text { sebelum pukul }\end{array}$ & $\begin{array}{l}\text { Waktu transfer } \\
\text { antar moda } \pm 3 \\
\text { Menit } \\
705.000 \\
\text { penumpang per } \\
\text { hari }\end{array}$ & $\begin{array}{l}\text { Jalur ganda sangat } \\
\text { membantu } \\
\text { memberikan } \\
\text { signifikansi } \\
\text { penambahan } \\
\text { frekuensi jumlah } \\
\text { bus dan jumlah } \\
\text { penumpang pada } \\
\text { jam sibuk } \\
>40 \% \text { pekerja }\end{array}$ & $\begin{array}{l}\text { Pengaplikasian } \\
\text { TPIS \& ITS } \\
\text { untuk } \\
\text { meningkatkan } \\
\text { kualitas Orange } \\
\text { Line } \\
\text { Pengurangan } \\
\text { waktu perjalanan } \\
\text { sebanyak } 7 \text { menit, } \\
\text { dan tingkat }\end{array}$ & $\begin{array}{l}\text { Impelementasi } \\
\text { jalur ganda untuk } \\
\text { beroperasi dan } \\
\text { menyalip } \\
1.600 .000 \\
\text { penumpang per } \\
\text { hari } \\
58 \% \text { dari total } \\
\text { keseluruhan }\end{array}$ & $\begin{array}{l}\text { Waktu tempuh } \\
\text { perjalanan } \\
\text { berangkat bekerja } \\
53,85 \% \text { berada } \\
\text { pada } 90-120 \\
\text { menit, dan } \\
38,46 \% \\
\text { menempuh jarak } \\
16-25 \mathrm{Km} \text { per } \\
\text { harinya }\end{array}$ \\
\hline
\end{tabular}




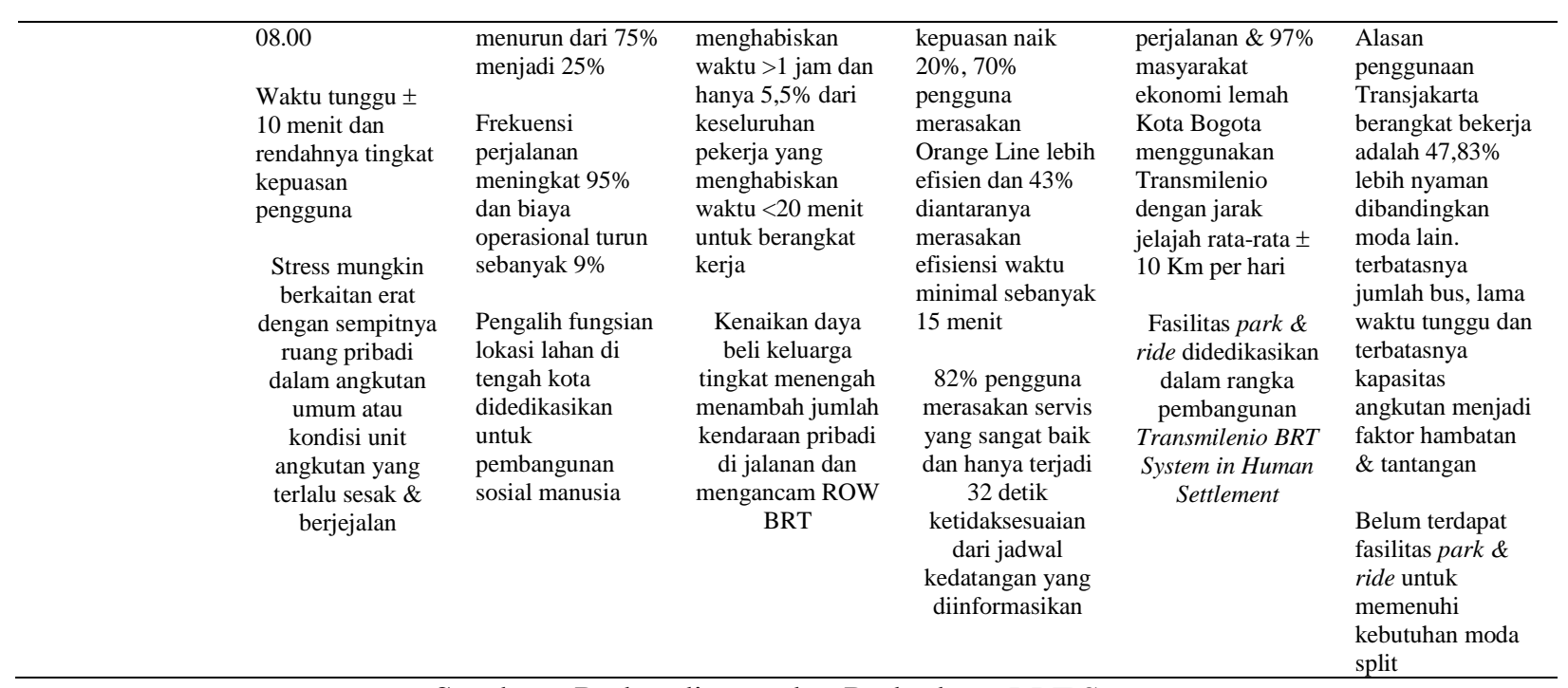

Sumber : Perbandingan dan Perbedaan BRT System

Terdapat persamaan pola perjalanan berangkat bekerja dengan menggunakan layanan transportasi BRT (bus rapid transit) bahwa penggunaan moda transportasi BRT dianggap mampu digunakan sebagai solusi atas kondisi jalanan yang semakin penuh dan tidak reliable nya waktu tempuh perjalanan berangkat bekerja bila menggunakan moda transportasi lainnya, khususnya transportasi pribadi. Persamaan penggunaan moda split pada pola perjalanan berangkat bekerja dengan menggunakan layanan BRT (buss rapid transit) identik dengan menggunakan moda transportasi yang tersedia pada lingkungan sekitar yang dianggap paling efektif dan efisien untuk mencapai tempat kerja. BRT (buss rapid transit) dipilih karena memiliki kedekatan jarak dengan lokasi hunian atau tempat tujuan. Kelebihan layanan transportasi Seoul BRT system adalah pengimplementasian sistem pembagian rute dan jaringan yang diperuntukkan agar waktu tempuh dan frekuensi perjalanan mencapai tingkat yang efektif serta tercapainya biaya operasional yang efisien. Hal ini diprioritaskan dengan tujuan sistem layanan transportasi Seoul BRT dapat melayani kebutuhan transportasi perkotaan yang baik dan memenuhi harapan para penggunanya untuk berangkat ke tempat kerja. Layanan transportasi Orange Line juga memiliki kelebihan pengimplementasian sistem TSP (transit signal priority) yang diperuntukan untuk memberikan tanda prioritas pada para pengguna jalan lainnya, sehingga Orange Line dapat didahulukan. Hal ini sebagai perwujudan bahwa transportasi umum yang mewakili pengguna kepentingan umum diberikan prioritas daripada pengguna kendaraan pribadi. Maka dari itu layanan Transjakarta perlu dapat mengevaluasi pemenuhan dedicated line dan implementasi jalur ganda R.O.W BRT seperti yang dilakukan pada Beijing BRT, Orange Line BRT dan Transmilenio Bogota yang dimaksudkan untuk memenuhi kebutuhan layanan transportasi umum yang baik bagi masyarakat perkotaan Kota Jakarta secara menyeluruh, sehingga evaluasi dan pengalih fungsian zonasi kota dapat dilakukan sebagai wujud perancangan pembangunan sosial masyarakat Kota Jakarta, hal ini juga mencontoh pada pembangunan Sungai Cheonggyecheon yang dimana pembangunannya diperuntukkan bagi pembangunan sosial masyarakat Kota Seoul, Korea Selatan.

\section{KESIMPULAN DAN SARAN}


Secara keseluruhan sarana dan prasarana layanan BRT Transjakarta saat ini masih banyak yang perlu dibenahi sehingga dapat memenuhi kebutuhan para penggunanya (kecepatan jelajah, fasilitas halte, design dan material yang digunakan, banyaknya jumlah bus serta sterilisasi jalur yang diperlukan). Layanan BRT Transjakarta untuk berangkat bekerja telah memberikan kontribusi positif atas penggunaan kendaraan pribadi sepeda motor yang hanya digunakan dalam radius $<5 \mathrm{Km}$ oleh para pengguna layanan BRT Transjakarta, tentu saja hal ini dapat menurunkan tingkat kecelakaan di jalan raya dengan moda yang dimaksud. Diperlukannya fasilitas park and ride disekitar halte Transjakarta sehingga dapat menunjang kemudahan mengakses layanan halte Transjakarta serta dapat menurunkan biaya perjalanan para penggunanya. Mengingat pola pemilihan moda para partisipan adalah menggunakan moda transportasi yang efisien yang tersedia dilingkungan sekitarnya, fasilitas ini juga dapat meningkatkan kecenderungan peralihan dari penggunaan moda transportasi pribadi ke layanan transportasi Transjakarta. Pelayanan transportasi BRT (buss rapid transit) Transjakarta juga dapat ditingkatkan menjadi pelayanan RTS (rapid transit system) dengan memberikan fokus pembenahan pada: 1) Speed incremental, 2) Dedicated lanes, 3) Frequent and reliable services, 4) Good stations, 5) Good vehicles, 6) Accomodations for people walking and biking, 7) Branding and finance. Hal ini sudah disuksesi pada beberapa kota seperti : Los Angeles (Orange Line), Seoul (SMRT), Bogota (Transmilenio).

\section{REFERENSI}

Bjork, Peter., Jansson, Therese. (2008). Travel Decision-making: The Role of Habit. Munich: Umea School of Busines.

Badan Pusat Statistik. (2018). Jakarta dalam Angka 2017. Jakarta: Badan Pusat Statistik Provinsi DKI Jakarta

Federal Transit Administration. (2011). Metro Orange Line BRT Project Evaluation. Los Angeles: Federal Transit Administration.

Fabio Duarte, Fernando Rojas \& D. Hidalgo, Intermodal Connectivity to BRT : A Comparative Analysis of Bogota and Curitiba, 2012. Bogota. \& Transmilenio:A High Capacity - Low Cost Bus Rapid Transit System Developed for Bogota, Colombia.

Hu, Hsi-Hwa., Lee, Kyoung. (2003). Travel Patterns Of The Elderly : The Role Of Land Use. California: University of Southern California.

Heather Allen, Bus Reform in Seoul, Republic of Korea. Case study prepared for the Global Report on Human Settlements, 2013.

Lecb, Undp. (2015). Bus Rapid Transit Development in Greater Jakarta (Jabodetabek). Jakarta: s.n.

Li, Linbo, et al. (2015). Case Study in Shanghai, China. Shanghai : American Society of Civil Engineers.

Majorsy, Ursa. (2010). Pattern Recognition. Jakarta: s.n.

Mairead Cantwell, Brian Caulfield, Margareth O'Mahony, Examining The Factors That Impact Public Transport Commuting Satisfaction, 2009. ISSN : 1077-291X.

National Research Council. (2012). Orange Line Bus Rapid Transit Sustainable Corridor Implementation Plan. Los Angeles: National Research Council. 
Priatmodjo, Danang. (1997). Studi Pola Jelajah, Jarak, Waktu, dan Biaya Tempuh dari Rumah Ke Tempat Bekerja Pada Penghuni Perumahan KPR-BTN di Pinggiran Kota Jakarta. Jakarta: Universitas Tarumanagara.

Seattle Department of Transportation. (2012). Madison BRT Corridor Study. Seattle: Seattle Gov. of Transportation.

Sugiyarto, Bambang. (2008). Analisis Pola Perjalanan Transportasi Penduduk Daerah pinggiran. Semarang: Universitas Negeri Semarang.

Tamin, Ofyar Z. (2008). Perencanaan dan Permodelan Transportasi. Bandung: Institute Teknologi Bandung.

Tao, Sui., Corcoran, Jonathan., Mateo-Babiano, Iderlina. (2016). Modelling Loyalty and Behavioral Change Intentions of Busway Passengers: A Case Study of Brisbane, Australia. Brisbane: IATSS Research

Taotao Deng, Mulan Ma, and Jing Wang, Evaluation of Bus Rapid Transit Implementation in China : Current Performance and Progress, 2013. DOI: 10.1061/(ASCE)UP.19435444.0000150. American Society of Civil Engineers

Wang, Zi-Jia., Chen, Feng., Xu, Tian-Kun. (2016). Interchange between Metro and other Modes : Access Distance and Catchment Area. Beijing: American Society of Civil Engineers. 